Artículos

\title{
El fin de una ilusión: la industria manufacturera mexicana después de los años ochenta
}

\section{The End of an Illusion: Post eighties Mexican Manufacturing Industry}

\author{
Rajchenberg S., Enrique
}

Enrique Rajchenberg $S$. enriquer@economia.unam.mx

Universidad Nacional Autónoma de México, México

Cuadernos de $\mathrm{H}$ ideas

Universidad Nacional de La Plata, Argentina

ISSN: 2313-9048

Periodicidad: Frecuencia continua

vol. 15, núm. 15, e047, 2021

cuadernosdehideas@perio.unlp.edu.ar

Recepción: 20 Marzo 2021

Aprobación: 05 Agosto 2021

URL: http://portal.amelica.org/ameli/jatsRepo/31/312012006/ index.html

DOI: https://doi.org/10.24215/23139048e047

\section{(1) $\$(0$}

Esta obra está bajo una Licencia Creative Commons AtribuciónNoComercial-CompartirIgual 4.0 Internacional.
Resumen: La década del ochenta del siglo pasado marcó el término de una ilusión largamente fomentada, la del acceso de México a la soberanía económica mediante la industrialización. A partir de ese momento, se insistió, en estricta sincronía con la matriz discursiva dominante, en las virtudes de la integración estrecha con los procesos productivos mundiales. El artículo describe las dimensiones de las transformaciones que reconfiguraron la industria manufacturera mexicana desde finales del siglo XX e inicios del nuevo siglo y que demuestran la profundización de las asimetrías del orden capitalista mundial.

Palabras clave: proyectos de industrialización, industrias automotriz y textil, reestructuración capitalista, maquiladoras.

Abstract: The eighties of the last century marked the end of a long-promoted illusion, that of Mexico's access to economic sovereignty through industrialisation. From that moment on, in strict synchrony with the dominant discursive matrix, the virtues of close integration with world production processes were insisted. The article describes the main features of the transformations that reconfigured the Mexican manufacturing industry since the end of the 20th century and the beginning of the new century that demonstrate the deepening of the asymmetries of the world capitalist order.

Keywords: Industrialisation projects, automotive and textile industries, capitalist restructuring.

Este texto es una suerte de epílogo o de capítulo final del libro La industria mexicana y su historia. Siglos XVIII, XIX y XX, publicado originalmente en 1997 y reeditado en forma virtual en 2018, en ambas ediciones por la UNAM. La obra original se detiene en los años ochenta. Está de más decir que los más de treinta años que nos separan de aquella década han representado un cambio de gran envergadura no sólo para el sector industrial, sino para el país en su conjunto.

El objetivo del presente artículo consiste en plantear algunas líneas de discusión sobre la vasta temática anunciada en el título y que ha adquirido gran complejidad a medida que este sector se diversificó e incorporó plenamente a la economía global. En esta coyuntura, finalizó la ilusión largamente mantenida de alcanzar la soberanía económica mediante la industrialización e inició, en cambio, el espejismo de un país que se incorporaría en igualdad de condiciones respecto a los grandes centros de poder económico 
a los encadenamientos productivos mundiales. No es mi propósito describir puntualmente la trayectoria de la industria manufacturera sacudida por diversas circunstancias, en absoluto desdeñables, durante las tres décadas que van de 1980 a 2010. Aunque el periodo que abordaré a continuación está marcado por ciertas coyunturas, tales como las crisis de 2000-2001 y de 2008-2009 en la economía de Estados Unidos con repercusiones graves en la industria mexicana, procuro caracterizar dicho periodo en su conjunto sin detenerme en los altibajos de la actividad manufacturera para, en cambio, dar cuenta de las tendencias que lo definen.

\section{LOS AÑOS PREVIOS}

La industria mexicana no nació al calor de una política económica industrializadora en los años cuarenta, como durante largo tiempo se afirmó, sino por lo menos medio siglo antes. Es a Stephen Haber $(1993)^{1}$ a quien le debemos la impugnación de esa interpretación historiográfico-económica al señalar que si en los años cuarenta la industria conoció tal expansión, ésta no pudo haberse producido ex--nihilo, sino sobre una base previa que el autor hace remontar a los años porfirianos. ${ }^{2}$ Una arqueología, más rigurosa incluso, de la industria ${ }^{3}$ reclamaría que los genuinos orígenes se localizan mucho antes de las décadas del ochenta y noventa del siglo XIX, ya que habría que incluir la semifallida (o semiexitosa?) experiencia del Banco de Avío y las emblemáticas Cocolápam, La Constancia Mexicana y algunas más. Otros más podrían alegar que los ferrocarriles, no obstante sus tropiezos iniciales, constituyeron el embrión más significativo de un proceso industrial en ciernes.

A pesar de estos cuestionamientos, es indudable que, a partir de la segunda mitad del siglo XX, la industria se vuelve el sector más dinámico de la economía mexicana. En otras palabras, México deja de ser un país fundamentalmente agrario y minero, aunque es el mundo rural el que paga buena parte de la factura de la industrialización a través de diversos mecanismos. ${ }^{4}$

El despliegue sin precedentes en la historia moderna de México de la industria es inexplicable sin la política industrializante de los gobiernos que se sucedieron desde aquel de Miguel Alemán que prohijó a un segmento considerable de la burguesía mexicana mediante exenciones arancelarias a la importación de maquinaria, un generoso proteccionismo, una política fiscal de privilegio y un corporativismo que así como concedía algunos beneficios a las clases trabajadoras urbanas, pálidos respecto a los del Welfare-State europeo, perseguía y reprimía todo intento de contradecir la austera política salarial de los años cincuenta, de fragilizar el monopolio político detentado por el partido oficial o aun de democratizar las organizaciones sindicales.

$\mathrm{Si}$ algunas, aunque no pocas voces, se alzaron impugnando la dimensión política del régimen, escasas fueron las que lo hicieron poniendo en tela de juicio las premisas económicas de la conducción estatal de la economía o los engranajes del patrón industrial o aun de la industrialización a marchas forzadas. Por ejemplo, José Luis Ceceña cuestionó la monopolización de la economía en manos de consorcios estadounidenses en escritos que datan de inicios de los cincuenta; ${ }^{5}$ Frank Tannenbaum (1951) recriminó en un texto con tintes semejantes al populismo ruso que la política industrializadora a toda costa obviaba la sustancia misma de la nación mexicana que residía básicamente en su campesinado y su sabiduría agrícola; etc. ${ }^{6}$ Mucho después se agregaron otros que demostraron cómo las asombrosas tasas de crecimiento económico se registraban al mismo tiempo que una cada vez más desigual distribución del ingreso. Y posteriormente, no pocos fueron los que teorizaron sobre la inviabilidad a largo plazo de una economía sustentada sobre pilares tan endebles, pero eso aconteció cuando la crisis era evidente. Del árbol caído es muy cómodo hacer leña.

El hecho de que fueron poco numerosas las posturas intelectuales discordantes debería advertirnos acerca del éxito que en el plano ideológico tuvo la política industrializadora que no solamente creó un significativo sector secundario, sino igualmente un mito industrializador que asociaba industria con soberanía económica e ingreso triunfal a la modernidad capitalista semisecular así como a un generalizado bienestar social. ${ }^{7}$ 
La industrialización se convirtió en emblema de aquello que los gobiernos posteriores a la Revolución de 1910 pudieron atribuir a la obra de ésta. Desde esta perspectiva, se vuelve inteligible por qué no se podía conceder a la época porfiriana el establecimiento de negociaciones fabriles: éstas debían ser una obra original de la Revolución.

Los gobiernos poscardenistas adoptaron una estrategia que, aunque no exclusiva de México, tuvo aquí una de sus expresiones más acabadas, a saber, la industrialización por sustitución de importaciones. Resulta superfluo regresar sobre su definición acerca de la cual han corrido ríos caudalosos de tinta. En cambio, es necesario destacar que incluso la manufactura de bienes de consumo nunca logró quebrar las relaciones de dependencia respecto a los centros mundiales del desarrollo industrial, ${ }^{8}$ sea porque se tuvo que acudir a los poderosos corporativos que detentaban la tecnología para la fabricación de una mercancía, sea porque algún insumo esencial estaba protegido por una patente o igualmente porque el ahorro interno era insuficiente respecto a los montos requeridos de inversión inicial. Por lo demás, los grandes monopolios estadounidenses y en menor medida los europeos se acomodaron a la sustitución de importaciones y a sus políticas proteccionistas implantando en el espacio económico nacional filiales de sus casas matrices, beneficiándose de esta manera de un mercado cautivo que, aunque con una capacidad adquisitiva inferior a la de sus países de origen, pagaba precios más elevados por los mismos bienes. Asimismo, la instalación en México de plantas fabriles permitió reciclar tecnología que ya estaba llegando al umbral de su vida socialmente útil en Estados Unidos y en Europa.

No se puede soslayar, sin embargo, que la ampliación y diversificación de la base industrial generó el crecimiento de la población obrera que fue adquiriendo altos niveles de calificación y, en algunos casos, de combatividad sindical, misma que le permitió el acceso a cláusulas contractuales favorables. Tampoco puede pasarse por alto que la estructura del comercio exterior mexicano se alteró de modo que los bienes de consumo duradero y no duradero y ciertos bienes intermedios dejaron de representar el grueso de las importaciones. Pero el pretendido impulso a la exportación de manufacturas con el cual se lograría equilibrar la balanza comercial no fructificó o lo hizo magramente.

\section{EL INGRESO A UNA NUEVA ÉPOCA}

Es habitual, en la vasta literatura económica sobre los años ochenta, una explicación del abandono de la estrategia industrializadora iniciada en los cuarenta basada en el viraje registrado en la política económica de los gobiernos. La secuencia cronológica de los hechos es grosso modo la siguiente. Las necesidades de la acumulación de capital al ser mayores que la capacidad de ahorro interno y de la recaudación tributaria condujo en el setenta a un creciente endeudamiento externo que se profundizó aún más a partir del descubrimiento de nuevos yacimientos de petróleo. El Estado, proveedor de bienes y servicios esenciales del sector privado, que había subsidiado a éste con tarifas por debajo de su costo de producción, se encontró sumido en una crisis financiera. Las considerables reservas petroleras de México fueron reveladas en una coyuntura particularmente favorable, la de la crisis petrolera provocada por el boicot de los países árabes y la decisión de la OPEP de incrementar el precio del barril. México, parecía, había momentáneamente sorteado una crisis que hubiera implicado la ruptura del tejido completo de relaciones económicas y políticas internas ya que se habría puesto en cuestión la viabilidad de los intereses de los grupos beneficiarios de la política económica anterior. Los préstamos fluyeron a México, en gran medida hacia la industria petrolera, en un momento en que las tasas de interés eran relativamente bajas y además, desde el punto de vista de los intereses estratégicos de Estados Unidos, asegurando de esta manera el abastecimiento del combustible a su economía. El sector industrial mexicano al que se reclamó la baja calidad de sus productos, los altos precios y su casi nula capacidad de exportación pudo sobrevivir por un breve tiempo más.

En medio de esa bonanza, se suscitó un debate sobre el destino que habría que otorgar a los inesperados recursos obtenidos por la exportación de petróleo. ${ }^{9}$ Los protagonistas de tal confrontación de propuestas 
fueron, por un lado, los altos funcionarios de la Secretaría de Patrimonio y Fomento Industrial asesorados por académicos de la Universidad de Cambridge y, por otro, aquellos del Banco de México y la Secretaría de Hacienda. Para los primeros se trataba de canalizar las divisas hacia la prosecución del desarrollo industrial procurando de este modo bajas tasas de desempleo y un aumento salarial; para los segundos, era imprescindible dedicar esos recursos a la garantía de los equilibrios macroeconómicos, además de tener que devaluar la moneda nacional y cumplir con el pago de la deuda externa. Poco tiempo después, la balanza se inclinó a favor de estos últimos, no tanto por la mayor cientificidad de su argumentación, sino por la súbita inflexión de las circunstancias económicas, como se explica a continuación.

Como es sabido, el espejismo petrolero se disolvió rápidamente: los precios del crudo cayeron estrepitosamente y, en sentido inverso, las tasas de interés subieron. La crisis de la deuda externa fue el catalizador del cuestionamiento más general de la estructura de toda la economía mexicana. La imposición por las instancias financieras internacionales de una reconfiguración de la economía mexicana fue, en estas circunstancias, una tarea facilitada por un sector del funcionariado económico del gobierno que compartía las recetas endilgadas. El margen de maniobra de la sociedad ante el "disciplinamiento" exigido era estrecho. La iniciativa lanzada por algunos movimientos sociales de declaración de una moratoria al pago de la deuda en alianza con otros países latinoamericanos fue desechada por el gobierno en turno. Fue así como inició el establecimiento de topes salariales estrictos, de recorte a los subsidios estatales al consumo popular, la disminución de los gastos sociales en los presupuestos públicos, la privatización de las empresas paraestatales y el ingreso de México al reino del libre comercio que se vería coronado un poco más de una década después con la firma del TLCAN. Este estuvo precedido por un alud de intervenciones de diversos personajes de la iniciativa privada y del sector público donde pudieron exhibir sin tapujos sus opiniones económicodarwinistas: "El coordinador del Grupo México del Consejo Mexicano de Hombres de Negocios, Francisco del Cueto, advirtió que los empresarios oportunistas e incapaces tendrían que desaparecer" (Garciadiego y otros, 1994, p. 108). ${ }^{10}$ Otros aprovecharon la oportunidad para expresar demandas que se verían satisfechas dos décadas más tarde: "El investigador Arturo Damm, miembro del Instituto Cultural Ludwig von Mises, afirmó que los llamados sectores estratégicos y básicos de la economía mexicana debían incluirse en las negociaciones del TLC, porque era necesario poner fin al monopolio gubernamental en el manejo económico de estos sectores" (Garciadiego y otros, 1994, p. 236). En todo caso, dos días después de culminada la negociación del tratado o sea el 14 de agosto de 1992, el secretario de SECOFI firmó el acta de defunción de la sustitución de importaciones así como el fin del proteccionismo comercial que en los hechos habían sido consumados paulatinamente desde la década del ochenta (Garciadiego y otros, 1994, p. 737). ${ }^{11}$

Aquello que fue plásticamente denominado adelgazamiento del Estado encubría una restructuración completa no sólo de las instancias públicas, sino igualmente una reconfiguración de la sociedad en su conjunto. Frecuentemente, se enfatiza cómo desde la década anterior se habían ido incorporando al sector público una nueva generación de cuadros, ya no egresados de las instituciones públicas de educación superior como en los tiempos del presidente Miguel Alemán (1946-1952) y sus sucesores, sino de universidades privadas o con posgrados en el extranjero, principalmente de Estados Unidos. Fieles aprendices de la teoría neoclásica, su arribo a las altas esferas del poder político les habría permitido aplicar rigurosamente las lecciones aprendidas allende el río Bravo. Fuera de duda de que las nuevas modalidades de reclutamiento del personal tecnoburocrático incidieron en las formas de conducción políticoeconómica, pero es preciso situar su incidencia en la avalancha de cambios ocurridos a partir de los años ochenta. Por una parte, este contingente no nació al calor de la crisis de esos años, sino que formó parte del impulso que la élite financiera e industrial otorgó a centros de enseñanza superior desde mucho tiempo atrás para contraponerse a los contenidos curriculares de sus homólogos públicos, como lo demuestra Romero Sotelo (2016). Por otra parte, sería sobreestimar la incidencia de estos neofuncionarios el convertirlos en únicos arquitectos de la construcción de las nuevas reglas del juego económico. 
En síntesis, la narrativa que intenta explicar el gran viraje de los años ochenta no está enteramente sesgada, sino que más bien no la hace anteceder por otro análisis, el de las profundas mutaciones del capitalismo, análisis previo que reordena y resignifica la importancia que cada uno de los fenómenos reseñados posee. En este sentido, las políticas económicas neoliberales no carecen de relevancia, pero éstas son resultado de las transformaciones transcurridas en otras instancias y que hacen del neoliberalismo algo más profundo que un conjunto de políticas públicas para devenir un modo de reorganización de la sociedad capitalista en su conjunto, en que la primacía de los valores de la competencia y del individualismo remplazan a la solidaridad y a los vínculos comunitarios.

\section{LA INDUSTRIA SE VUELVE MAQUILADORA}

Los límites alcanzados por las formas fordistas de producción para incrementar la productividad en un contexto de creciente cuestionamiento obrero de la cadena de montaje, del cronometraje de los gestos de trabajo, de intensificación del mismo, etc. condujeron a trastocar las pautas fundamentales de organización de la fábrica, pero más globalmente de los mecanismos de obtención de la ganancia. Los pasos agigantados realizados en materia de comunicaciones facilitaron la consumación de la estrategia reestructuradora.

Las aplicaciones de estas innovaciones a la producción manufacturera permitieron la deslocalización de fases completas de los procesos de fabricación estableciendo una nueva división internacional del trabajo que no eliminó las asimetrías del orden mundial anterior, sino que las reforzó y agudizó. Según los bienes en cuestión, las sedes de las grandes corporaciones multinacionales se reservaron fases como el diseño, la comercialización y la distribución. Las decisiones de inversión, esto es, de establecimiento de una planta en un país están determinadas por múltiples factores, entre los que el nivel salarial es sólo uno de ellos y no necesariamente el principal ${ }^{12}$ como lo fue a mediados de los años sesenta cuando se instalaron en México las primeras plantas maquiladoras de ensamblaje de prendas de vestir. Lo son, en cambio, la disponibilidad de mano de obra calificada, la infraestructura en comunicaciones y transporte, la legislación en materia fiscal, arancelaria, ambiental, etc. (Álvarez Herrera, 2009).

Para México, las consecuencias de esta reestructuración capitalista no fueron de poca envergadura. Significaba abandonar un proyecto económico centrado en el dinamismo del mercado interno y adoptar un "esquema" en que la estrecha articulación con los requerimientos de las corporaciones transnacionales hacía del sector externo la fuente del crecimiento. Se podría entonces a partir de ese momento vanagloriarse de haber logrado el anhelado intento de exportación manufacturera tantas veces frustrado durante las décadas del sesenta y setenta. La diferencia radicaría en que el contenido de las exportaciones y el perfil del sector manufacturero estaría determinado por las estrategias de valorización de los monopolios extranjeros, como acertadamente lo señalan Jaén Jiménez y León Sánchez (2009).

Detengámonos en una de las dimensiones más controversiales de esa restructuración con fuertes implicaciones para la industria manufacturera mexicana. Es frecuente la caracterización de la industria manufacturera actual, sino es que de la economía en su conjunto, como de maquilización y que ha sido objeto de atención de numerosos investigadores. ${ }^{13}$ Con ello se procura destacar la supeditación de la actividad económica mexicana a designios extranjeros y la asignación a ésta de las fases más degradantes de los procesos de fabricación. En ese sentido, posee más una intención ideológica que una propuesta conceptual rigurosa. Desde el punto de vista metodológico, la maquiladora debe ser definida como un proceso sujeto a transformaciones a lo largo del tiempo: poca similitud guarda un taller de ensamble de prendas de vestir de los años sesenta con una planta productora de motores de automóviles para la exportación inaugurada en el siglo XXI, aunque ello no significa que aquel haya desaparecido. Al contrario, las maquiladoras de tercera, cuarta o quinta generación pueden tener en su entorno otras de primera generación que la abastecen de 
ciertos insumos. ${ }^{14}$ No son un arcaísmo que irá desapareciendo con el tiempo, sino un ingrediente funcional del sistema maquilador en su conjunto.

¿Acaso hay algún denominador común entre ambos, el taller de ensamble y la gran planta automotriz? La respuesta depende de cómo se defina a la maquiladora. Si adoptamos la propuesta de Jorge Carrillo, profundo conocedor de la economía industrial de la frontera norte, quien la consigna fundamentalmente como "un régimen arancelario en el cual se inscriben las empresas con el fin de poder importar temporalmente libre de impuestos, los insumos, componentes, maquinaria y equipo necesarios (así como el traslado de personal técnico extranjero) para producir un bien o servicio en México y re-exportarlo hacia Estados Unidos" (Carrillo y Hualde, 1997, p. 748). ${ }^{15}$, tendríamos que excluir a los talleres enteramente volcados al mercado interno para confección de ropa o de ensamble de zapatos deportivos que requieren de fases intensivas en trabajo. En estos casos, la maquiladora no se define por su orientación al mercado externo ni por los beneficios arancelarios. Desde mi punto de vista, es una definición restrictiva y que únicamente hace hincapié en la dimensión fiscal, aun si ésta tiene una repercusión económica decisiva. Sin embargo, es pertinente su énfasis en los muy diversos tipos de maquiladora existentes y que, según él, pueden ser estudiados como generaciones de maquilas, mismas que son contemporáneas y no sucesivas en el tiempo. ${ }^{16}$

$\mathrm{Si}$, en cambio, restringimos el significado de la maquiladora al referente, que puede comportar niveles diversos de complejidad, del ensamble de piezas, cuya figura icónica es precisamente el taller de prendas de vestir o la fábrica de juguetes, deberíamos reservar la designación a formas que van desde las más "primitivas" de las manufacturas implantadas en la frontera norte principal, aunque no exclusivamente, hasta otras más complejas como las de la electrónica e informática, constituidas en clusters donde laboran ingenieros con formación universitaria de posgrado (Dabat y otros, 2005).

El común denominador de ambos, el taller de ensamble y la gran planta automotriz, es el carácter de su producción sobredeterminada desde el exterior cuya articulación global escapa al control de las instancias nacionales, gubernamentales o no: qué se producirá, cómo, en cuánto tiempo, con qué materiales, en qué cantidad, etc. son decisiones resueltas por las grandes corporaciones, aun si el fabricante local propone las características del producto, mismas que quedan sujetas a la aprobación y exigencias de aquellas. ${ }^{17}$

Esto es lo que ha dado lugar a la modalidad llamada de paquete completo, contrato que implica que el fabricante que trabaja a cuenta de una gran corporación transnacional asume todas las fases de la producción de un bien. Hay que señalar, no obstante, que puede conducir al equívoco implícito en la noción del escalamiento productivo (upgrading), que para algunos investigadores tiene como correlato el cierre paulatino de la brecha ( gap) entre los países desarrollados y los dependientes puesto que la contribución de éstos a la cadena global de valor aumenta. ${ }^{18}$ Ya no es sólo el salario, por lo general bajo, de los obreros y obreras y de los técnicos o la energía eléctrica, lo que se adiciona al valor de las piezas importadas por ensamblar, sino la remuneración de una fuerza de trabajo muy calificada que diseña el software por ejemplo, así como el de insumos nacionales, aun si éstos siguen siendo una proporción pequeña del total. Así, la descripción de la industria electrónica en el área conurbada de Guadalajara desde mediados de los años ochenta, a la que se ha denominado coloquialmente el Silicon Valley mexicano, impulsada por la IBM en sus inicios, parecería no diferir de los resultados que arrojaría un estudio análogo en California. ${ }^{19}$ Pueden encontrarse en esta ciudad del occidente mexicano empresas cuya mano de obra más significativa son los ingenieros que desarrollan productos de alta sofisticación tecnológica y que mantienen vínculos interempresariales con otras plantas que, a su vez, se ocupan del embalaje del producto o de la inyección de plástico. Es decir, la IBM u otra transnacional delega a un conjunto de empresas mexicanas o también extranjeras, bajo estricta supervisión, la fabricación de equipos de cómputo u otros productos electrónicos. Dejando de lado las condiciones de trabajo que imperan en las subcontratistas de las empresas encargadas del diseño que pueden ser muy semejantes a las maquiladoras de primera generación, no es tan relevante destacar cuántos escalones falta 
por ascender para alcanzar o incluso rebasar a los más adelantados como detenerse en otra dimensión de la dinámica capitalista.

Indudablemente, estamos algo distantes de la teorización que Fröbel, Heinrich y Kreye (1981) propusieron de la división internacional del trabajo a principios de los años ochenta. ${ }^{20}$ Es decir, esta división no asigna únicamente a los países dependientes funciones que implican mano de obra sin calificación, mal pagada, etc. mientras otros se reservan aquellas que conciernen a la concepción del producto y a las fases menos sucias del proceso de trabajo. Pero ello no significa un mundo sin profundas diferencias entre el Norte y el Sur bajo la égida del primero.

Hay algo aun más insidioso en el nuevo perfil de la división internacional del trabajo que es visible en la industria de las prendas de vestir, pero no solamente. Estados Unidos desplazó hacia el Sur sus fábricas, pero también en ocasiones cerró contratos de paquete completo. Sin embargo, se reserva algo: la marca. Las transnacionales del vestido, propietarias de las marcas Tomy Hilfiger, Levi's o Nautica probablemente no produzcan en Estados Unidos o en otra parte del mundo más que una pequeña fracción de lo que colocan en el mercado. Son las marcas la fuente de sus ganancias: el símbolo genera a su creador una renta. Las marcas son la forma fetichizada contemporánea de la mercancía; son el correlato del mismo fetichismo del capital cuya forma culminante es la del capital financiero: D-D', dinero que adquiere la facultad de incrementarse sin pasar por una fase intermedia. Lo mismo sucede con las marcas que producen una renta sin "ensuciarse las manos" en la producción. Si Keynes en un momento refirió la necesaria eutanasia del rentista para reactivar el ciclo económico suprimiendo el parasitismo antiproductivo, hoy habría que plantearse tal vez la eutanasia, obviamente económica, del rentista de la marca, es decir, un mundo no logo como lo denomina Naomi Klein (2001).

\section{LA INDUSTRIA MANUFACTURERA MEXICANA EN EL NUEVO CONTEXTO}

Nuestro estudio se detendrá particularmente en dos ramas de la industria, la automotriz y la textil. Tanto acerca de una como de la otra existe una vasta literatura que nos permitirá, sin pretender generalizaciones simplificadoras, dar cuenta de las nuevas coordenadas que rigen a la industria manufacturera. Por lo demás, se trata de ramas emblemáticas de la vorágine exportadora y maquiladora, aunque cada una con grados disímbolos de modernidad tecnológica. En efecto, mientras que la industria de la confección es catalogada como una actividad que emplea equipos arcaicos en algunos talleres, la automotriz ha incorporado los desarrollos de la informática, de nuevos materiales y, muy particularmente, ha sido campo de aplicación de inéditos modos de gestión de la fuerza de trabajo.

No abordaremos el universo completo de las problemáticas que caracterizan a la industria manufacturera mexicana, sino que nos concentraremos en algunos tópicos que, desde nuestra perspectiva, reseñan adecuadamente los procesos socioeconómicos de esta actividad económica y dan cuenta de importantes cambios ocurridos en ella.

\section{¿Feminización del empleo industrial?}

La incorporación de las mujeres al trabajo fabril es un fenómeno del siglo XX. Por supuesto, antes del inicio de esa centuria, las mujeres ocuparon puestos con porcentajes elevados respecto al empleo masculino en el textil. ¿Cómo olvidar las páginas que Marx consagró a la brutal explotación de mujeres adultas e infantes en las manufacturas durante el siglo XIX inglés? Pero en el caso de México, esto se presentó mucho más tarde o de manera minoritaria antes. ${ }^{21}$ En Europa occidental, las mujeres se incorporaron a las industrias pesadas metalúrgica y armamentista, por ejemplo- durante las guerras mundiales mientras los varones se encontraban 
en el frente de batalla. Al regreso de éstos, volvieron a sus lugares sociales anteriores o se incorporaron al comercio y a los servicios (educación, enfermería, por ejemplo).

En México, se ha asociado el trabajo femenino asalariado a las coyunturas económicas recesivas, vale decir, la pérdida del trabajo por los varones o la insuficiencia del ingreso familiar habría empujado a las mujeres a su inserción en el mercado laboral. Fue así como tras la crisis de 1982, la presencia de mujeres en la industria de la construcción fue notoria cuando antes de esa fecha era de poca cuantía, aunque un aumento sustancial en los salarios industriales llegan a ser un factor en el aumento de la participación de las mujeres en el trabajo fabril, como sostienen Cordourier y Gómez Galvarriato, siempre y cuando no haya otras barreras a su incorporación. ${ }^{22}$ La explicación residiría en el costo oportunidad que representa incorporarse al trabajo industrial respecto a la realización de labores domésticas o artesanales no remuneradas. Sin embargo, hay determinantes sociológicos en el ingreso de las mujeres a la fábrica que no se rigen únicamente por un cálculo racional, tal como lo concibe la teoría neoclásica, como lo veremos un poco más adelante.

En términos porcentuales, la participación de las mujeres en el total del personal ocupado en la industria manufacturera no se modificó durante la primera década del nuevo siglo. Se mantuvo en 35\%. Asimismo, en la fabricación de prendas de vestir se estabiliza la proporción de mujeres, aun si se registra un leve descenso, de $59.5 \%$ a 58\%. En cambio, en lo que concierne a la fabricación de equipo de transporte el decremento es más notorio, de 38 a 34\%, y, más específicamente, en la fabricación de automóviles y camiones donde su presencia es decididamente minoritaria -de 11a 9.4\%- (Inegi, 1999, 2004, 2009). En la industria de autopartes, la participación de las mujeres es mayor, alcanzando el $38 \%$ del total del personal ocupado. Vale decir que las mujeres aun si presentes en el sector automotriz, lo están en las empresas subcontratistas sobre todo donde las remuneraciones, la estabilidad en el empleo y las condiciones de trabajo son inferiores a las prevalecientes en las unidades terminales de la fabricación de equipo de transporte.

En el ámbito que aquí nos interesa, hay que destacar la casi sinonimia que la literatura académica estableció entre maquiladoras y obreras. Efectivamente, el emblema de aquellas fue desde su implantación a mediados de los sesenta el ensamblaje de prendas de vestir, un trabajo que coincide con el estereotipo de las mujeres en la realización de tareas domésticas, ahora extendidas al terreno de la fábrica. Hubo empero otras actividades donde las mujeres eran mayoritarias, tal el caso de la selección y enlatado de productos del mar, mismos que igualmente pueden parecer una extensión de las labores domésticas. Al diversificarse la industria maquiladora, las mujeres podían ser encontradas también en la electrónica.

En cualquiera de estos casos, varias características podían ser compartidas: el origen rural reciente de ellas, sus antecedentes en el servicio doméstico urbano, su edad -población joven-, las condiciones de trabajo extenuantes con su correlato de alta morbilidad profesional y mortalidad, la baja o nula tasa de sindicalización, el escaso número de puestos técnicos y de obreros calificados ocupados mayoritariamente por varones, etc.

La sofisticación tecnológica que acompañó el arribo de nuevos productos por maquilar, como lo fueron partes de la fabricación de armamento para el ejército de Estados Unidos, requirió de trabajadores más calificados y de una infraestructura fabril con características precisas ya que se trata de bienes que no admiten márgenes de error, es decir, deben ser de calidad total. En ese tipo de maquiladoras, la proporción entre obreros y obreras se alteró en favor de los primeros. Ello no significa que ellas no figuraron más en el personal ocupado, sino que su participación relativa decreció. En 1980, las obreras representaban el 77\% del total de obreros de la industria maquiladora de exportación; en 2006, esta proporción había disminuido al 54\%. ${ }^{23}$ Entre estas mismas dos fechas, el número de técnicos de la maquiladora se multiplicó por 14, llegando a representar más del 13\% del total del personal ocupado. Aun si existen mujeres técnicas asalariadas en la industria maquiladora, son resueltamente minoritarias. Estaríamos entonces ante un fenómeno de desplazamiento relativo de las mujeres de esta industria concomitante a la complejización tecnológica de la maquiladora, en que la movilidad ascendente para las mujeres en las fábricas es mucho más restringida que para los varones. $^{24}$ 
En la rama automotriz y específicamente en las fábricas que se instalaron en México a partir de la liberalización de la inversión extranjera o, ulteriormente de la firma del TLCAN, el fenómeno se presenta del siguiente modo. El ejemplo de la Volvo estudiado por un equipo sueco de investigación (Räthzel, Mulinari y Tollefsen, 2014) en cuatro países donde la empresa posee plantas es revelador, aun si ello no nos autoriza a generalizarlo. En el caso de México, las mujeres obreras representan un pequeño porcentaje en el total de trabajadores adscritos a la producción directa. Su ingreso a alguna de las fases del proceso de trabajo es significado por ellas como un paso agigantado en el reconocimiento social ya que las labores desempeñadas en el hogar no son consideradas un trabajo; sólo lo son las remuneradas y, sobre todo, aquellas convencionalmente asignadas a los varones. De ahí que atestigüen un sentimiento de orgullo porque además de demostrar la habilidad necesaria para ocupar el puesto, generalmente tras un breve periodo de capacitación, revierten el estereotipo atribuido a las mujeres como sexo débil que las confina en el seno de la fábrica a tareas de limpieza. Para ellos en cambio, pasar de un trabajo manual a otro administrativo o de supervisión representa un ascenso en la escala jerárquica y social.

Ahora bien, las relaciones de género que subalternizan a las mujeres en la sociedad no son una construcción de las empresas transnacionales, aunque sí son instrumentalizadas por éstas de dos maneras. ${ }^{25}$ Por un lado, generan una división en el seno del colectivo de trabajadores quebrando el frente de resistencia que podrían éstos esgrimir unificadamente. Por otro lado, se apropian de las habilidades que las mujeres desarrollan al cumplir las tareas que la división por género del trabajo les impone para racionalizar el número de efectivos contratados e incrementar la intensidad del trabajo. La ardua combinación del trabajo doméstico con el asalariado, lo que suele llamarse la doble o triple jornada, implica una organización y planificación de la jornada, habilidades que aprovechadas en el mundo fabril permitió a Volvo remplazar en algunos casos dos hombres con una sola mujer. ${ }^{26}$

\section{Nuevas geografías económicas}

Muy a pesar de las apologéticas retóricas globalófilas de los años noventa del siglo pasado, el espacio económico y social está lejos de representar un dato indiferenciado para el capital. Más aún, la creencia de que el libre comercio termina felizmente en la abolición de fronteras nacionales es igualmente falsa: la globalización, aun si articula todos los rincones del planeta y los subordina a una misma lógica económica, no culmina en una organización ecuménica del mundo ni tampoco en la eliminación de las disparidades regionales en el seno de un mismo territorio nacional. ${ }^{27}$

En este sentido, la localización de las plantas productivas en espacios donde previamente no habían tenido una presencia relevante obedece al interés por aprovechar determinados recursos naturales, sociales, etc. Sin embargo, su utilización depende de marcos institucionales que facilitan u obstaculizan su empleo, sea tal como están dados o que se modifiquen en arreglo a las condiciones requeridas por el capital. Dichos marcos están, hoy por hoy, enunciados por los Estados quienes, por ejemplo, urgidos por atraer la inversión de capital extranjero, modifican los términos legales que norman la operación de las empresas de modo a hacer atractivo un país como campo de inversión. La mera puesta en competencia entre Estados es suficiente para rebajar los requisitos e incrementar las facilidades que benefician a los capitales foráneos o nativos.

La firma del TLCAN reforzó un rasgo de la economía mexicana que quedó soldado desde finales de la Segunda Guerra Mundial, a saber, el de convertirse en una función de la economía estadounidense. Lo que fue presentado como una magnífica oportunidad de aprovechar el ingreso al mercado más grande del mundo, fue y es la ventaja de las corporaciones estadounidenses pero también chinas, coreanas, europeas, de acogerse a regímenes fiscales, salariales, ambientales más laxos que en sus países de origen reforzados por la proximidad geográfica que implica una de las fronteras terrestres más extensas del mundo. ${ }^{28}$ 
Es así como los últimos veinte o veinticinco años dieron lugar a una relocalización de la industria manufacturera ubicada durante el medio siglo anterior fundamentalmente en el centro del país. La ubicación respondía a la proximidad con el mayor número de consumidores de la economía mexicana de aquel entonces, así como la mayor disponibilidad de vías de comunicación, de proveedores, etc. Fue una de las críticas más acerbas que se formularon a la política industrial de aquellos años, ya que agudizó las disparidades regionales en materia de empleo y productividad.

Las maquiladoras instaladas desde mediados de los años sesenta se ubicaron en la frontera norte por las mismas razones. Puesto que la producción era enteramente para el mercado estadounidense, resultaba ventajoso reducir los costos de transporte situándose a pocos metros de la línea fronteriza. De hecho, muchas maquiladoras que arribaron en los decenios ulteriores se instalaron igualmente en Tijuana, Nuevo Laredo, Reynosa, Matamoros o en Ciudad Juárez, entre otras ciudades fronterizas. A medida que los parques industriales se fueron saturando, los últimos en llegar optaron por asentarse en lugares relativamente distantes de la frontera, aunque a pocas horas de distancia por vía terrestre. En otros casos, se escogió por ejemplo a la península de Yucatán que a pesar de estar distante del río Bravo se conecta en poco tiempo de recorrido aéreo con el estado de Florida.

Sin embargo, es de particular interés la inversión en la industria automotriz a partir de los noventa. Esta puede ser de tipo maquilador o no. Al igual que la industria manufacturera en su conjunto, desde su implantación en México, su principal localización había sido la ciudad de México y su zona conurbada del contiguo estado de México (la empresa MASA, por ejemplo) y el estado de Hidalgo (el caso de Dina en Ciudad Sahagún). Ulteriormente, otras empresas se instalaron en el valle de Toluca y en Puebla, la gigantesca Volkswagen. Las nuevas inversiones se realizaron, en cambio, en el norte o en el centro norte del país, en Aguascalientes la fábrica Nissan y en Coahuila, Sonora y Chihuahua. Si en 1980, el sector automotriz representaba el 9.6\% del valor agregado censal bruto de la capital del país, en 2009, sólo era de $1.5 \%$. De manera contrastante, en Chihuahua, ese porcentaje era del $4 \%$ para la primera fecha y de $30.3 \%$ para la segunda, mientras que en Coahuila el salto fue de proporciones semejantes: de $2.6 \%$ a $36.7 \%$ (Carbajal, Almonte y Mejía, 2016). En términos más globales, el cambio se hizo evidente en los diez años transcurridos entre 1993 y 2002: la frontera norte que aportaba el 25\% del PIB manufacturero nacional, pasó a contribuir con el $28.4 \%$ mientras que el centro pasó de $46.9 \%$ al $42.3 \%$ y la región del Golfo de 5.9\% a 5.2\% (Evolución del sector manufacturero, 2004).

Como es habitual en la industria automotriz, junto a la gran empresa existe una cadena de proveedores cuyos establecimientos son de menor tamaño y que la abastecen en partes del producto final. Es la rama productora de autopartes que puede ser de propiedad extranjera al igual que la empresa terminal y cuyos vaivenes están pautados por los que sacuden a ésta. La rama en cuestión se movió junto con sus grandes clientes que, por lo demás, pueden encontrarse del otro lado de la frontera.

La nueva fisonomía geoeconómica acarrea un desplazamiento demográfico que, sin todavía alterar el milenario patrón de asentamiento humano en el altiplano central, sí implica una mayor densidad de población en el norte, realizando el viejo sueño de colonización de ese inmenso territorio de los políticos e ideólogos del siglo XIX. No obstante, una paradoja histórica se ha producido porque los personajes del siglo antepasado concebían la colonización del poco habitado Septentrión como un medio de evitar la sujeción o incluso la anexión de ese territorio mexicano por Estados Unidos. Lo que ha sucedido es que el crecimiento demográfico del Norte se produce a través de una integración subordinada a la economía estadounidense.

\section{¿Desindustrialización?}

Así como el léxico crítico de los ochenta incluyó la noción de adelgazamiento del Estado a la cual me he referido antes, obtuvo popularidad la de desindustrialización que, desde mi punto de vista, puede vehicular un equívoco peligroso, ya que induce la idea de que el número de plantas fabriles se contrae. 
El ingreso de México al GATT comportaba la amenaza de la ruina y consecuente cierre de empresas industriales mexicanas que durante varias décadas habían sobrevivido o también prosperado al abrigo de una política arancelaria proteccionista y también prohibicionista. Esta les había permitido aislarse del mercado mundial y neutralizar la potencial competencia de productores extranjeros. El contrabando debilitaba parcialmente esta fortaleza monopsónica, aunque nunca al grado de alterar los patrones productivos y tecnológicos de la industria, así como su política de precios relativamente elevados respecto a los vigentes en el mercado estadounidense. El arribo de mercancías desde la otra orilla del Bravo o aun de China ulteriormente llevaría a alterar las prácticas industriales acostumbradas o bien a desaparecer, algo que aconteció en buen número de ramas.

Ello no significó sin embargo la disminución de empresas cuyo número no decreció. Lo que sí se alteró fue el tejido industrial que es propiamente lo que debería entenderse por desindustrialización. En otras palabras, puede suscitarse un proceso desindustrializador sin que se registre un número inferior de establecimientos industriales.

El tejido industrial y su densidad o, en términos gráficos, la cantidad de hilos de su urdimbre, puede ser estudiado a través de los encadenamientos productivos establecidos entre las ramas. Su desgarramiento y su debilitamiento configuran una desindustrialización.

Dos investigaciones particularmente, a través de un análisis de los eslabonamientos hacia atrás de la industria manufacturera en su conjunto y de la industria automotriz, básicamente de la rama terminal y de la de autopartes, dan cuenta de cómo se ha desenvuelto la relación entre éstas y sus proveedores de insumos a partir de la liberalización comercial y de la inversión extranjera.

El estudio realizado por Jorge $\mathrm{O}$. Tellitud (2008). se concentra en las dos ramas mencionadas de la industria automotriz entre 1970 y el año 2004 lo cual le permite comparar el desempeño de ambas durante el periodo en que se promovió la integración nacional de esta industria y aquel en que se abandonó esa política. Es así como demuestra que si hasta los ochenta la rama de autopartes y en menor medida la terminal incorporaban insumos nacionales en proporciones cada vez mayores, a partir de 1990 esta tendencia se revirtió. La rama de autos y camiones, autopartes, equipo de cómputo así como motores importa más del 50\% de sus insumos. ${ }^{29}$

Veamos algunos ejemplos. Entre 1982 y 1989, la tasa media de crecimiento anual de las importaciones de automóviles para el transporte de personas fue de -1.3\%, mientras que entre 1990 y 2004, la tasa registró un aumento de $26 \%$. Para las mismas fechas, en lo que respecta a los chasises para automóviles, las cifras son $-3.1 \%$ y $37.2 \%$, por una parte, y de $6.6 \%$ y $24.9 \%$ para motores y sus partes para automóvil. Su análisis de la matriz insumo producto de 1990 arroja que "el contenido de insumos de origen nacional integrados en los automóviles bajó respecto a 1980 en $41.7 \%$ y la participación de las importaciones en el total de insumos incorporados aumentó en 90.9\%; la incorporación de autopartes nacionales se redujo $45.43 \%$ respecto a 1980" (Tellitud, 2008, p. 137). En lo que concierne a la industria de autopartes, "la proporción de insumos importados se incrementó 101.69\%”" (Tellitud, 2008, p. 137).

La segunda investigación lleva a cabo una indagación muy detallada del comercio exterior de México por mercancías desglosadas hasta ocho dígitos en las clasificaciones internacionales (Manzanares, 2008). Ello permite descubrir que las exportaciones e importaciones "mayoritariamente están compuestas de productos incompletos, sin terminar” (Manzanares, 2008, p. 117). Tres observaciones relevantes sobre la actividad manufacturera y el comercio exterior tipifican el estatuto conferido a los productores mexicanos dentro de las cadenas globales:

Existe una escasa vinculación con proveedores a nivel nacional...Existe una gran dependencia de las importaciones, trátese de las materias primas, partes, componentes o subensamblajes...El sector manufacturero bajo este dinamismo exportador se ha especializado en procesos de ensamblaje y subensamblaje. La principal aportación al valor agregado se refiere a la mano de obra barata, a algunos insumos productivos manufactureros, que incluyen gastos de embalaje, servicios como alquiler, teléfono, electricidad (Manzanares, 2008, p. 120). 
Las conclusiones de los dos investigadores citados parecen contradecir una de las afirmaciones contundentes de un documento muy consultado por los especialistas de este tema, a saber, El tratado de libre comercio de América del Norte en la transformación de la industria del vestido: ¿bendición o castigo? de Gary Gereffi (2000). Éste descarta por ser un mito (sic) que las maquiladoras utilizan sólo insumos importados, aunque reconoce que el 98\% de los insumos sí lo son. Sucede que, según el mismo autor, a diferencia de los establecimientos localizados en la frontera, aquellos instalados en el interior del país sí tenderían a emplear mayor cantidad de insumos nacionales. Lamentablemente, no proporciona datos acerca de esta supuesta tendencia; solamente destaca que las grandes corporaciones del vestido de Estados Unidos, propietarias de marcas afamadas se están deshaciendo de sus fábricas en ese país ${ }^{30}$ pactando con empresas mexicanas acuerdos de paquete completo que implican que estas últimas se hacen cargo del abastecimiento de hilos, telas, del ensamblaje, etc. En términos generales, Manzanares arriba a la conclusión de que la industria no maquiladora importa más que la maquiladora, lo cual reduce su impacto exportador aun si, por ejemplo, la automotriz y la electrónica registran los más altos valores de exportación.

Volvamos a la pregunta inicial, a saber, ¿estamos acaso presenciando un proceso de desindustrialización tal como hemos definido la noción más arriba? La respuesta no puede ser unívoca porque la diversidad de condiciones es amplia, de acuerdo a la rama manufacturera en cuestión e incluso en razón de la región. Empero, en lo que concierne a las actividades manufactureras más dinámicas como lo es la automotriz, parece evidente el desgarramiento del tejido industrial que implicaba hasta los años ochenta cierto grado de encadenamientos productivos hacia atrás. La situación puede ser más matizada en el textil, aunque hay que considerar que se trata de una actividad no estratégica en términos de la competencia mundial, que el control de la comercialización y de las marcas sigue estando en manos de grandes corporaciones estadounidenses y que, por último, aun si se ha innovado en tecnología, permanece como una rama intensiva en trabajo.

\section{CONSIDERACIONES FINALES}

La industria estuvo en el centro del debate políticoeconómico desde el nacimiento de México como república independiente. ¿Era el pasaporte que permitiría franquear la puerta hacia una era poscolonial en que se brindaría a todos los ciudadanos una condición de vida sin penurias al mismo tiempo que el país afirmaría su soberanía? ¿Era necesario que el poder público interviniera para fomentar la actividad industrial ya que sin una participación de aquel no se lograría el efecto deseado? ¿Bastaba con una regulación aduanera? Hay consenso en la historiografía actual que para delinear la trayectoria de la industria en México es preciso remontarse al siglo XIX cuando estas preguntas se formularon y se discutieron, pero también cuando las primeras plantas fabriles iniciaron sus operaciones en medio de un sinnúmero de obstáculos.

A finales del siglo XIX, se asistió a pasos más veloces del despliegue industrial. Ciertamente el Estado apoyó a los comerciantes devenidos empresarios industriales, aunque fue un respaldo indirecto mediante el recurso a las tarifas arancelarias que encarecían las importaciones de manufacturas respecto a las nacionales. Pero ese apoyo no bastaba para remover la barrera más alta que se alzaba a un desarrollo industrial más extenso. Las relaciones sociales que el régimen admitía y preservaba lo impedían: salarios miserables y una población mayoritariamente rural sujeta a condiciones de casi servidumbre en muchos casos no eran el almácigo más fértil para el establecimiento de una red industrial extensa. Por esa razón, los industriales intentaron compensar la estrechez del mercado interno con la búsqueda de compradores en el extranjero. El esfuerzo fue infructuoso.

La revolución estallada en 1910 trastocó a lo largo de los decenios siguientes el ordenamiento social en el campo y reglamentó las relaciones obrero-patronales en el mundo urbano. La dramática distribución desigual del ingreso no se invirtió totalmente, pero sí fue alterada creando la posibilidad de ampliar el mercado para los bienes de origen industrial. La institucionalidad estatal creada para impulsar al sector de marras fue el ingrediente nodal: Nafinsa; un amplio sector paraestatal que creó infraestructura y generó bienes y 
servicios para la industria; el encapsulamiento de las clases populares en el seno del partido de Estado fueron engranajes indispensables, como se mencionó en páginas anteriores, para que el sector industrial llegara a representar casi una cuarta parte del producto interno bruto. ¿Podía continuar este proceso industrializador hacia otras fases más complejas? Ello implicaba un cuestionamiento de todo el camino andado y de un magno redireccionamiento en el que se hubiera tenido que revisar desde los beneficios fiscales otorgados a los empresarios hasta el tipo de bienes producidos no en función de un estricto criterio de alta y pronta rentabilidad, sino de las necesidades sociales.

La corrección arribó, pero no como resultado de un amplio debate interno, sino forzado, obligado, por las grandes instituciones financieras, los intereses de las corporaciones transnacionales y sus aliados en México que desde tiempo atrás venían promulgando su ideario, en el marco de una reestructuración capitalista que incluyó a México en el rediseño de las estrategias globales de valorización. Estas implicaron el desmantelamiento de una parte sustancial del tejido industrial, así como la obsolescencia social de su mano de obra. Esta nueva inserción del país en los engranajes de la producción mundial vino acompañada de un andamiaje ideológico que, inspirado en la caída del muro de Berlín, sostenía igualmente el derrumbe de las asimetrías implícitas en el ordenamiento mundial.

Entre tanto, la industria manufacturera se convirtió en un apéndice de los requerimientos de los grandes monopolios estadounidenses y en menor medida europeos y asiáticos, operando bajo los lineamientos emitidos por ellos. Así es como buena parte del tan codiciado "éxito" exportador está basado en realidad en la importación de componentes de productos o en la fabricación de sus partes. De esta manera, la actividad maquiladora acotada hace treinta y cuarenta años a ciertas ramas de la industria manufacturera más ligera alcanza ahora a la electrónica, la automotriz, reconfigurando la geografía económica del país.

El estudio del impacto que esta reestructuración tiene sobre el proletariado industrial deberá ser objeto de otro artículo, aunque ya ha sido abordado por varios investigadores. Me he limitado aquí a referir escuetamente la dimensión de género que entraña la nueva orientación de la industria manufacturera mexicana.

Desde mi perspectiva, repensar el camino andado implica sin falta asumir que colocándose en el patrón tecnológico-industrial cuyas posiciones de poder ya están ocupadas y firmemente acaparadas constituye un esfuerzo vano si de alcanzar la autodeterminación económica se trata. Esta consideración podría parecer una reiteración trasnochada de los postulados liberales mexicanos de la primera mitad del siglo XIX quienes, opuestos a la promoción de actividades económicas consideradas "artificiales" porque no se gestarían naturalmente en estas comarcas como la minería y la agricultura, rechazaban los proyectos de industrialización y, al contrario, adoptaban la perspectiva ricardiana de las ventajas comparativas.

No es esa mi matriz argumental. Lo que sostengo no es una postura anti-industrialista, sino que hago hincapié en que el seguimiento de las pautas del desarrollo industrial tal y como se verificaron en los países europeos y en el estadounidense no puede conducir al logro de los objetivos declarados de autodeterminación económica amén de otros propósitos. Ello implica una reinvención y redefinición de lo que industrialización significa y puede ser. En todo caso, resulta ya inadmisible social y éticamente una industrialización que se procese sobre las espaldas de un sector de la sociedad, como aconteció con los campesinos, y ecológicamente irresponsable y destructora de la naturaleza. En ese sentido, ciertos actores de la agricultura, a la que el desarrollismo consideraba atrasada per se y para el cual el indicador del progreso era la disminución de su participación en el PIB, se han anticipado al universo urbano-industrial al crear formas de producción, de distribución y de comercialización que apropiándose de los avances no depredadores de la ciencia y la tecnología modernas y recuperando simultáneamente conocimientos antiguos desafían el patrón tecnológico e incluso el paradigma civilizatorio dominante. 


\section{Agradecimientos}

Agradezco la valiosa colaboración de Valeria López, así como los generosos comentarios de María Eugenia Romero Sotelo.

\section{ReFERENCIAS}

Aguayo, F. y Salas, C. (2002). Reestructuración y dinámica del empleo en México. 1980-1998, Región y sociedad, 25(14). https://doi.org/10.22198/rys.2002.25.a682

Álvarez Herrera, M. (2009). La localización: estrategias diferenciadas de las empresas textil-confección en la franja fronteriza de Tamaulipas (Tesis de doctorado). Universidad Nacional Autónoma de México. Recuperado de https://repositorio.unam.mx/contenidos/la-localizacion-estrategias-diferenciadas-de-las-empresas-textil-co nfeccion-en-la-franja-fronteriza-de-tamaulipas-65095?c=YYaqA3\&d=false\&q=*:*\&i=1\&v=1\&t=search_1\& as $=0$

Arteaga, A. (2003). Integración productiva y relaciones laborales en la industria automotriz en México. Ciudad de México, México: Universidad Autónoma Metropolitana/Plaza y Valdés.

Calva, J. L. (2020). La economía mexicana en su laberinto neoliberal. El Trimestre económico, 343(XXXVI). https:/ /doi.org/10.20430/ete.v86i343.921

Carbajal, Y., Almonte, L. y Mejía, P. (2016). La manufactura y la industria automotriz en cuatro regiones de México. Un análisis de su dinámica de crecimiento, 1980-2014. Economía: teoría y práctica, (45), 39-66. Recuperado de http://www.scielo.org.mx/scielo.php?pid=S0188-33802016000200039\&script=sci_abstract

Carrillo, J. y Hualde, A. (1997). Maquiladoras de tercera generación. El caso de Delphi-General Motors, Comercio Exterior, 9(47), 747-757.

Carrillo, J. y Lara, A. (2003). ¿Maquiladoras de cuarta generación? Coordinación centralizada. Ponencia presentada en el Cuarto Congreso Nacional de Estudios del Trabajo. Recuperado de http://www2.izt.uam.mx/sotraem/Documentos/Documentos/Amet2003/templates/res/tema\%2013/JO RGE\%20CARRILLO-ARTURO\%20LARA.pdf

Ceceña, J. L. (1963). El capital monopolista y la economía mexicana. Ciudad de México, México: Cuadernos Americanos.

Cordourier, G. y Gómez-Galvarriato, A. (2004). La evolución de la participación laboral de las mujeres en la industria: una visión de largo plazo. Economía mexicana. Nueva Época, XIII(1), 63-104. Recuperado de https://www.red alyc.org/articulo.oa?id=32313104

Cypher, J. y Delgado Wise, R. (2007). El modelo de exportación de fuerza de trabajo barata en México. Economia UNAM, 12(4), 23-41. Recuperado de http://www.revistas.unam.mx/index.php/ecu/article/view/2924

Dabat, A. y otros (2005). La reestructuración del cluster electrónico de Guadalajara (México) y el nuevo aprendizaje tecnológico. Problemas del desarrollo, 143(36), 89-111. Recuperado de http://ru.iiec.unam.mx/id/eprint/135

de la O, M. E. (2006). El trabajo de las mujeres en la industria maquiladora de México: balance de cuatro décadas de estudio. AIBR. Revista de Antropología Iberoamericana, 3(1), 404-427. Recuperado de https://imumi.org/docu mentos/Mujeres_en_la_industria_maquiladora-balance_cuatro_decadas_2006.pdf

Escamilla Trejo, A. (2015). El complejo industrial Sahagún(1952-1995). Ciudad de México, México: Universidad Nacional Autónoma de México (UNAM).

Evolución del sector manufacturero de México. 1980-2003 (diciembre 2004). Cámara de Diputados, Centro de Estudios de las Finanzas Públicas.

Fröbel, F., Heinrich, J. y Kreye, O. (1981). La nueva división internacional del trabajo: paro estructural en los paises industrializados e industrialización de los paises en desarrollo. Ciudad de México, México: Siglo XXI.

Galeano, E. (2008). Espejos. Ciudad de México, México: Siglo XXI. 
Garciadiego, J. y otros (1994).El TLC día a día. Crónica de una negociación. Ciudad de México, México: Miguel Ángel Porrúa.

Gereffi, G. (2000). El tratado de libre comercio de América del Norte en la transformación de la industria del vestido: ¿bendición o castigo? Serie Desarrollo Productivo, 3. Santiago de Chile, Chile: Comisión Económica para América Latina y el Caribe (CEPAL).

Haber, S. (1993). La industrialización de México: historiografía y análisis. Historia mexicana, 3(XLII).

INEGI (1999, 2004, 2009). Censos económicos. Ciudad de México, México: Instituto Nacional de Estadística y Geografía.

Jaén Jiménez, B. y León Sánchez, M. (2005). La industria electrónica de exportación en Jalisco, México. Comercio Exterior, 3(55), 270-281. Recuperado de http://revistas.bancomext.gob.mx/rce/magazines/76/6/RCE.pdf

Klein, N. (2001). No logo: el poder de las marcas. Ciudad de México, México: Paidós.

Manzanares, M. (2008). La inserción del sector manufacturero mexicano en la economía mundial, 1995-2006 (Tesis de maestría). Facultad de Economía, Universidad Nacional Autónoma de México (UNAM). Recuperado de http: //132.248.9.41:8880/jspui/handle/DGB_UNAM/TES01000632398

Merchand, A. (2003). La maquilización de la economía. México: de país productor a país ensamblador. Revista de Ciencias Sociales de la Universidad Autónoma de Nuevo León, (12).

Moreno-Brid, J. C. y otros (2021). Trade agreements and decent work in Mexico: the case of automotive and textile industries. Ginebra, Suiza: ILO Working Papers.

Novelo, V. (1983). Arqueología de la industria en México. Ciudad de México, México: Museo de Culturas Populares.

Räthzel, N., Mulinari, D. y Tollefsen, A. (2014). Transnational Corporations from the Standpoint of Workers. Londres, Gran Bretaña: Palgrave Macmillan.

Rajchenberg, E. (1999). ¿Milpas o chimeneas? La polémica en torno a la industrialización a mediados de siglo en México en el siglo XX. Ciudad de México, México: Archivo General de la Nación.

Rajchenberg, E. (2014). José Luis Ceceña y la inversión extranjera. En M. E. Romero Sotelo, L. Ludlow y J. P. Arroyo (Coords.), El legado intelectual de los economistas mexicanos (pp. 635-654). Ciudad de México, México: Universidad Nacional Autónoma de México (UNAM).

Rajchenberg, E. (2016). El capital monopolista y la economía mexicana en su escenario. En A. E. Ceceña y R. Ornelas (Coords.), Las corporaciones y la economía-mundo (pp. 230-247). Ciudad de México, México: Siglo XXI/ Universidad Nacional Autónoma de México (UNAM).

Romero Sotelo, M. A. (2016). Los orígenes del neoliberalismo en México. Ciudad de México, México: Fondo de Cultura Económica.

Romero Sotelo, M. A. (s/f). Grupo de Cambridge y la tradición del desarrollismo en México (1977-1982). Un breve recuento (mimeo).

Tannenbaum, F. (1951). México: La lucha por la paz y el pan. Problemas agricolas e industriales de México, 3(4).

Tellitud, J. (2008). El desarrollo dependiente de la industria del automóvil en México (Tesis de maestría). Facultad de Economía, Universidad Nacional Autónoma de México (UNAM). Recuperado de http://132.248.9.41:8880/ jspui/handle/DGB_UNAM/TES01000632867

\section{Notas}

1 Nos situábamos en la misma tesitura crítica que los autores del libro citado.

2 Ello conducía también a desbaratar los binomios convencionales porfirismo-arcaísmo económico, y gobiernos posrevolucionarios-modernidad industrial.

3 Tal el ya clásico libro coordinado por Victoria Novelo (1983).

4 Se trataba de que el sector agrícola subsidiara a la industria mediante el abastecimiento a bajo precio de bienes de subsistencia de la población trabajadora urbana, la provisión de divisas mediante la exportación y de la producción de materias primas igualmente a precios reducidos para la industria. 
5 Aunque estuvo precedida por varios artículos, la investigación completa fue publicada en 1963 (Rajchenberg, 2014 y 2016).

6 Un análisis del texto y del debate que desató en Rajchenberg (1999).

7 El mito no es una narración mentirosa o engañosa. Es un relato compartido por una comunidad que puede referirse tanto al origen común como a su destino y a las estrategias para construirlo. Ese es el sentido que confiero a lo que denomino el mito industrializador.

8 Los intentos de integración nacional de la industria automotriz impulsados por el Estado durante las décadas del sesenta y setenta -en gran medida infructuosos- son analizados por Arnulfo Arteaga (2003). Igualmente, un estudio profundo del Complejo Industrial Sahagún, productor de camiones y de trenes del metro en Escamilla Trejo (2015).

9 La controversia ha sido estudiada por María Eugenia Romero Sotelo (s/f, mimeo).

10 En el mismo tono, el director del Centro de Estudios Económicos del Sector Privado declaró que "desaparecerían empresas nacionales grandes, medianas y pequeñas, en la medida en que fueran incapaces de adaptarse a los niveles de productividad y eficiencia, que un mundo interdependiente imponía cada día” (Garciadiego et al., 1994, p. 113).

11 "En los primeros años de la década del ochenta, México instrumentó un viraje de gran envergadura en su estrategia económica en favor de una reforma del mercado. Abandonó la tradicional agenda de desarrollo orientada por el Estado para abrir unilateralmente el mercado doméstico a la competencia extranjera” (Moreno-Brid et al., 2021, p. 7).

12 Aunque las diferencias salariales entre México y Estados Unidos, ya no se diga con Europa, tras las devaluaciones del peso, hicieron muy atractiva la inversión en este país.

13 Entre muchos otros, Calva (2020), Cypher y Delgado W. (2007) y Merchand (2003).

14 De hecho, la polémica noción de generación de maquilas, como la define Jorge Carrillo, implica la contemporaneidad de varias generaciones. Ver igualmente la argumentación de Aguayo y Salas (2002).

15 En un texto posterior, Carrillo se referirá a maquiladoras de cuarta generación que son aquellas que "evolucionan rápidamente hacia la incorporación de nuevas actividades basadas en la coordinación y las tecnologías de información" (Carrillo y Lara, 2003).

16 No obstante, difiero del organicismo de su concepto de generación de maquiladoras que lo hace plantear que éstas "mutan, aprenden, se reestructuran, se re-localizan e incluso mueren" (Carrillo y Lara, 2003, p. 2).

17 Hay autores que subestiman este hecho argumentando que la territorialidad nacional o los mismos Estados-nación westfalianos son realidades ya inexistentes y que, por lo tanto, es indistinto si se trata de capital foráneo o nacional. No discutiré esa postura aquí, pero considero importante enfatizar que, como mencioné antes, sigue reproduciéndose una división internacional del trabajo que asigna lugares jerárquicamente organizados a los diversos espacios de valorización del capital.

18 La metáfora de la escalera y de los escalones ascendidos conduce a una postura histórico-económica errónea. Como nos lo recuerda Eduardo Galeano (2008, p. 197), Daniel Defoe celebró el proteccionismo británico que resultó provechoso para desarrollar su industria textil. Una vez alcanzado el objetivo, "la potencia imperial fue prohibiendo, por asfixia o a cañonazos, que otros países siguieran su camino. -Cuando llegó arriba, pateó la escalera- dijo el economista alemán Friedrich List”. Por ello mismo, Ulises Grant, quien fue presidente de Estados Unidos en los años setenta del siglo XIX, dijo: "Dentro de doscientos años cuando hayamos obtenido del proteccionismo todo lo que nos puede ofrecer, también nosotros adoptaremos la libertad de comercio" (Galeano, 2008, p. 201).

19 Una muy buena descripción de la industria en Jaén Jiménez y León Sánchez (2005).

20 Es menester reconocer que los tres autores visibilizaron para el análisis del capitalismo contemporáneo la progresiva deslocalización de la producción industrial, mucho antes que adquiriera credenciales académicas el concepto de globalización.

21 Sin embargo, las diferencias regionales de la participación de las mujeres en el trabajo industrial fueron importantes. Destacan durante la primera mitad del siglo XX las regiones norte y occidente del país. Ver Cordourier y GómezGalvarriato (2004).

22 Tales como la resistencia de las organizaciones sindicales a que las mujeres ocupen puestos habitualmente masculinos.

23 En 1975, por cada 28 hombres había 100 mujeres contratadas en las maquiladoras; en 2004, la proporción se había modificado a 86 hombres por cada 100 mujeres (de la O, 2006).

24 Este panorama, que conduce a María Eugenia de la $\mathrm{O}$ a definirlo como una refeminización del trabajo maquilador, es diferente al que predomina en las maquiladoras del centro y sur de México, donde las mujeres siguen siendo ampliamente mayoritarias. Ello se debe a que estas plantas ensambladoras pertenecen a las llamadas de primera generación consagradas, entre otros, a las prendas de vestir.

25 Por esta razón no concuerdo con las conclusiones de dos investigadoras mencionadas anteriormente: “...Las empresas extranjeras siguen prácticas laborales menos discriminatorias hacia las mujeres” (Cordourier y Gómez-Galvarriato, 2004, p. 91). Precisamente, el caso de Volvo es relevante porque, de acuerdo al espacio socioeconómico de implantación de sus unidades fabriles, la política laboral de la empresa respecto a las mujeres se acomoda al contexto no sólo jurídico de igualdad formal de hombres y mujeres en el trabajo, sino también y sobre todo de reconocimiento social de la equidad 


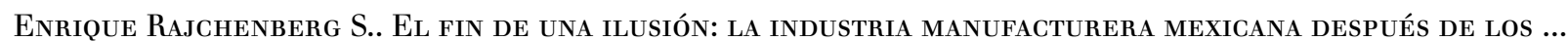

de género. En ese sentido, no es lo mismo la experiencia laboral de las mujeres obreras de Volvo en Suecia que aquella en México o en Sudáfrica.

26 En una de las entrevistas realizadas por las investigadoras suecas a las obreras de la Volvo, Elena, una de ellas, comenta con orgullo: "La satisfacción de hacer un buen trabajo, un trabajo que demandaba dos trabajadores y que ahora puedo hacer yo sola. Sí, la satisfacción que puedo hacerlo. Es porque nosotras las mujeres hacemos las cosas prolijamente, somos más movidas. Como en la casa. Ellas llegan a la casa y lavan la ropa y piensan en el día siguiente. Tenemos un ritmo. Los hombres no" (Räthzel, Mulinari y Tollefsen, 2014, p. 158).

27 Una demostración amplia de la persistencia de las diferencias regionales y una crítica a las propuestas teóricas que sostienen la paulatina homogeneización de las regiones en Aguayo y Salas (2002).

28 Varios programas gubernamentales destinados a promover las exportaciones contenían beneficios jugosos para las empresas que se colocaran exitosamente en los mercados externos (PITEX y ALTEX).

29 Durante la primera década de este siglo, los insumos importados representaron el $78 \%$ de la producción maquiladora.

30 Por esa razón, se dice que son fabricantes sin fábricas. 